\title{
Using network clustering to predict copy number variations associated with health disparities
}

Yi Jiang, Hong Qin, Li Yang

Substantial health disparities exist between African Americans and Caucasians in the United States. Copy number variations (CNVs) are one form of human genetic variations that have been linked with complex diseases and often occur at different frequencies among African Americans and Caucasian populations. Here, we aimed to investigate whether CNVs with differential frequencies can contribute to health disparities from the perspective of gene networks. We inferred network clusters from human gene/protein networks based on two different data sources. We then evaluated each network cluster for the occurrences of known pathogenic genes and genes located in CNVs with different population frequencies, and used false discovery rates to rank network clusters. This approach let us identify five clusters enriched with known pathogenic genes and with genes located in CNVs with different frequencies between African Americans and Caucasians. These clustering patterns predict two candidate causal genes located in four population-specific CNVs that play potential roles in health disparities 
1 Using network clustering to predict copy number variations

2 associated with health disparities.

3 Yi Jiang*

4 Department of Computer Science and Engineering, University of Tennessee at

5 Chattanooga, TN

6 Hong Qin*s

7 Department of Biology, Spelman College, Atlanta, GA

8 Li Yang

9 Department of Computer Science and Engineering, University of Tennessee at

10 Chattanooga, TN

$11 *$ Co-first authors.

12 § Corresponding author. Phone: (404) 270-5757, Fax: (404) 270-5725, Email:

13 hqin@spelman.edu 


\section{Abstract}

15 Substantial health disparities exist between African Americans and

16 Caucasians in the United States. Copy number variations (CNVs) are one form

17 of human genetic variations that have been linked with complex diseases and

18 often occur at different frequencies among African Americans and Caucasian

19 populations. Here, we aimed to investigate whether CNVs with differential

20 frequencies can contribute to health disparities from the perspective of gene

21 networks. We inferred network clusters from human gene/protein networks

22 based on two different data sources. We then evaluated each network cluster

23 for the occurrences of known pathogenic genes and genes located in CNVs

24 with different population frequencies, and used false discovery rates to rank

25 network clusters. This approach let us identify five clusters enriched with

26 known pathogenic genes and with genes located in CNVs with different

27 frequencies between African Americans and Caucasians. These clustering

28 patterns predict two candidate causal genes located in four population-

29 specific CNVs that play potential roles in health disparities.

30 Keywords:

31 Health disparities, Copy Number Variations (CNVs), gene network, clustering,

32 gene-disease association, Gene Ontology (GO). 


\section{List of Key Abbreviations:}

34 CNV: Copy number variation

35 SNP: Single nucleotide polymorphism

36 PPIN: Protein-protein interaction network

37 HPRD: Human protein reference database

38 PPI: Protein-protein interaction

39 AA: African American

40 MCL: Markov Cluster Algorithm

41 FDR: false discovery rate

42 GO: Gene ontology

43 OMIM: Online Mendelian Inheritance in Man

44 dbSNP: Single Nucleotide Polymorphism Database

45 SERCA1: Sarco/endoplasmic reticulum $\mathrm{Ca}^{2+}$-ATPase 1 


\section{Introduction}

47 Health disparities refer to differences in the disease distribution and/or health

48 outcomes across racial and ethnic groups. In the United States, health

49 disparities in African Americans are found in life expectancy, death rates, and

50 health measures (National Center for Health Statistics 2013). In addition to

51 social determinants, such as socio-economical status, health care access and

52 cultural practices, human genetic variations play a significant role in health

53 disparities. Genetic variations at different frequencies among populations can

54 lead to differences in disease susceptibility. Studies on genetic variations and

55 disease association are greatly advanced by the completion of the

56 International HapMap Project and new genome sequencing techniques

57 (Ramos \& Rotimi 2009).

58 Genome-wide association studies (GWAS) are currently an effective approach

59 to identify disease-associated genetic variations (Hirschhorn \& Daly 2005;

60 Wang et al. 2005). Although GWAS have revealed many disease-associated

61 single nucleotide polymorphisms (SNPs), GWAS are often limited to individual

62 genetic variations and often do not address complex gene interactions.

63 Moreover, associated SNPs are often located in haplotype blocks that contain

64 more than one gene. To address these limitations, human gene networks

65 have been used to improve GWAS detection of genes associated with

66 complex diseases, such as the comorbidity analysis (Sharma et al. 2013), an

67 improved guilt-by-association method (Baranzini et al. 2009; Lee et al. 2011), 
68 and a distance-based scoring method using seeded diseases genes (Liu et al.

69 2012).

70 Copy number variations (CNVs) are duplications or deletions of genomic

71 segments that can contain one or more genes (McCarroll \& Altshuler 2007).

72 CNVs have been associated with complex diseases such as autism (Gilman et

73 al. 2011; Glessner et al. 2009). Computational tools and methods, such as

74 the CNV annotator (Zhao \& Zhao 2013) and NETBAG (Gilman et al. 2011),

75 have been developed to address the potential roles of CNVs in human

76 diseases. Recently, it was reported that CNVs can occur at different

77 frequencies between African Americans and Caucasians (McElroy et al. 2009),

78 and naturally the question about the potential roles of CNVs in health

79 disparity is raised.

80 Here, we aim to investigate the clustering of pathogenic genes and genes in

81 CNVs with different population frequencies in two human gene/protein

82 networks, in order to better understand health disparities between African

83 Americans and Caucasians. The current human gene/protein networks

84 contain thousands of interacting molecules (Barabasi et al. 2011; Vidal et al.

85 2011). We will partition gene networks into clusters and use these clusters to

86 predict potential diseases associated with population-specific CNVs, based on

87 the rationale that interacting genes often share similar functions (Pizzuti et 88 al. 2012).

89 Materials and Methods 
90 Our overall work flow is shown in Figure 1 . To identify potential diseases

91 associated with CNVs, our basic idea is to identify gene interaction clusters

92 that involve genes in population-specific CNVs. The diseases associated with

93 a CNV-gene's interacting genes are potential diseases associated with this

94 CNV. Specifically, we first obtained two human gene/protein networks and

95 partitioned them into gene clusters. We then performed statistical tests on

96 each cluster to estimate its significances of containing pathogenic genes and

97 genes in population-specific CNVs. Finally, we ranked gene clusters based on

98 false discovery rates (FDRs). High-ranked clusters were enriched both for

99 pathogenic genes and for genes in CNVs with differential frequencies

100 between African-Americans and Caucasians. These clusters were then

101 searched for enriched Gene Ontology (GO) terms and related disease

102 phenotypes.

\section{Network clustering}

104 We obtained two human gene/protein networks, one from Human Protein

105 Reference Database (HPRD) (Mishra et al. 2006; Peri et al. 2003; Prasad et al.

106 2009) and another from MultiNet (Khurana et al. 2013). The HPRD network

107 (referred to as HPRDNet) contains only physical protein-protein interactions

108 (PPIs), whereas MultiNet is a unified network including PPI, phosphorylation,

109 metabolic, signaling, genetic and regulatory networks. These two networks

110 share 8468 genes ( $89.6 \%$ of HPRDNet and $58.6 \%$ of MultiNet) but only 8769

111 interactions (23.8\% of HPRDNet and $8 \%$ of MultiNet). These two networks

112 were both partitioned into gene clusters using the Markov Cluster (MCL) 
113 Algorithm (van Dongen 2000). Clustering was done with the inflation

114 parameter I ranging from 1.1 to 2.0 with a step of 0.1 . Descriptive statistics

115 of the two networks and their clustering results are summarized in

116 Supporting Table S1.

\section{Mapping of CNVs and SNPs}

118 CNV coordinates were obtained from a CNV map in African Americans and

119 Caucasians (McElroy et al. 2009). There are three types of CNVs in this map:

120 (1) CNVs only occurred in African Americans, (2) CNVs only occurred in

121 Caucasians, and (3) CNVs occurred in both African Americans and

122 Caucasians. To simplify the analysis, we further partitioned the last type:

123 CNVs that occurred more than $50 \%$ in African Americans or in Caucasians

124 were combined with the first and second types of CNVs, respectively. This

125 repartition resulted in two modified CNV sets with differential population

126 frequencies. The coordinates of these CNVs were then searched in the UCSC

127 Genome Database (Karolchik et al. 2014) through its MySQL API to obtain the

128 corresponding gene sets. For simplicity, CNVs that occur more frequently in

129 African Americans were called African-American CNVs or CNV_AA; CNVs that

130 occur more frequently in Caucasians were called Caucasian CNVs or CNV_CA.

131 Disease-associated SNPs were retrieved from a file, OmimVarLocusldSNP.bcp,

132 from the FTP site of Single Nucleotide Polymorphism Database (dbSNP)

133 (Sherry et al. 2001). Coordinates of these SNPs were then queried against the 
134 MySQL API of the UCSC Genome Database to identify genes in which those

135 SNPs are located. This identified gene set was termed as pathogenic genes.

136 Details of gene mapping results are shown in Supporting Table S2.

\section{Cluster Analyses}

138 Clusters were obtained from both HPRDNet and MultiNet using MCL with a

139 range of ten inflation parameters. For each cluster, contingency tables were

140 constructed using the numbers of pathogenic genes and CNVs related genes

141 (Table 1A and 1B). Right-tailed Fisher's exact tests were applied to these

142 contingency tables to calculate enrichment significance of pathogenic genes,

143 and CNV_AA or CNV_CA genes, respectively. Based on obtained $p$-values,

144 false discovery rates (FDRs) were calculated using the Robust FDR Routine

145 (Pounds \& Cheng 2006). Fisher's exact tests and Robust FDR Routine were

146 both performed in the R statistical environment ( $R$ Development Core Team

147 2013). Ranking was applied to clusters with $p$-value $<0.10$ and FDR $<0.20$ in

148 both enrichment tests for pathogenic genes and population-preferred CNVs

149 genes. Assuming both enrichment tests are independent, the FDR values

150 were multiplied to jointly rank the network clusters. The same cluster

151 analysis procedure was applied to clustering results with different MCL

152 inflation parameters. 
153 For clarity, we focused our functional analyses on clusters that were

154 consistently ranked at the first place with different MCL inflation parameter

155 values.

\section{Biological Significance Analyses}

157 Biological relevance of selected network clusters were analyzed by GOrilla

158 (Eden et al. 2009) to search for enriched gene ontology (GO) terms. In GOrilla

159 search, genes in the selected clusters were target genes, and all genes in the

160 network were treated as background genes. To investigate the possible links

161 of population-specific CNVs to heath disparities, we first identified

162 significantly enriched GO terms that are associated with CNV_AA or CNV_CA

163 genes. We then focused on the pathogenic genes related to the enriched GO

164 terms, and examined their associated disease phenotypes in OMIM database

165 (Online Mendelian Inheritance in Man 2014).

\section{Results and Discussions}

\section{Top-ranked network clusters}

168 We performed cluster analyses with ten MCL inflation parameter values for

169 both HPRDNet and MultiNet (Table S1), and scored the resulted clusters for

170 their potential roles in CNV related health disparities (Table S3). For clarity,

171 we focused on clusters that are consistently top-ranked with different MCL

172 inflation parameters. The graph representations of selected clusters are

173 shown in Figure 2. 
174 We found four similar clusters, (AA1, AA2, and AA3 in HPRDNet and AA4 in

175 Multinet), that are enriched both for pathogenic genes and for genes located

176 in African-American CNVs (Table 2). In HPRDNet, cluster AA1, AA2 and AA3

177 together were ranked at first place five times; and cluster AA4 were ranked

178 five times in Multinet (Table S3). Cluster AA1 contains 11 genes, within which

179 eight are pathogenic genes (Figure 2A). Cluster AA2 and AA3 contain one and

180 two more genes than cluster AA1, respectively (Figure S1). In MultiNet,

181 cluster AA4 contains five genes and can be considered as a sub-cluster of

182 cluster AA1, AA2 and AA3 (Figure $2 \mathrm{~B}$ ). In these four clusters, gene HSPB1 is

183 mainly duplicated in African Americans (Table 2 and Table 3). Based on GO

184 enrichment tests, this family of clusters was found to be involved in visual

185 perception and eye development. Since cluster AA1, AA2 and AA3 were

186 selected from the same network and are highly similar to each other, only

187 cluster AA1 and AA4 will be discussed further for their potential roles in

188 health disparities.

189 In both HPRDNet and MultiNet, the same cluster, named as CA1, was

190 identified to be enriched with both pathogenic genes and genes located in

191 Caucasian CNVs (Table 2). Cluster CA1 was ranked at first place four times in

192 HPRDNet and seven times in MultiNet (Table S3). This cluster contains five

193 genes, and four of them are associated with diseases (Figure 2C). The GO

194 term enrichment tests suggested that cluster CA1 was involved in calcium

195 ion transportation and muscle contraction regulation. Cluster CA1 contains

196 gene ATP2A1 that is duplicated only in Caucasians (Table 3). 
197 Duplication of HSPB1 and health disparities in African Americans.

198 Gene HSPB1 is located in genomic duplication regions occurring more

199 frequently in African Americans (Table 3), and is found in the cluster family of

200 AA1, AA2, AA3, and AA4 (Table 2). For cluster AA1, only one GO molecular

201 function term related to gene HSPB1 is significantly enriched (Cluster AA1 in

202 Table 4). For cluster AA4, in addition to the same enriched GO molecular

203 functions term, three GO biological process terms and one GO cellular

204 component term are found significantly enriched (Cluster AA4 in Table 4). In

205 the genes with the enriched GO terms, four of them are known to be

206 associated with diseases (Cluster AA1/AA4 in Table 5). Among these four

207 genes, three of them are implicated in health disparities of African

208 Americans. Specifically, gene CRYAB is related to dilated cardiomyopathy and

209 myofibrillar myopathy. African Americans were found at higher risk for

210 idiopathic dilated cardiomyopathy compared with Caucasian, and this could

211 not be explained by income, education, alcohol use, smoking, or history of

212 some other diseases (Coughlin et al. 1993). Moreover, gene CRYAA, CRYAB

213 and $C R Y B B 2$ are all related to various types of cataract. It was reported that

214 age-specific blindness prevalence was higher for African Americans compared

215 with Caucasian, and cataract accounts for $36.8 \%$ of all blindness in African

216 American, but for only 8.7\% in Caucasian (Congdon et al. 2004).

217 How could HSPB1 duplication contribute to health disparities? Based on the

218 direct interaction between HSPBI and CRYAB and the fact that both genes

219 are expressed in Z-disc (Table 4), it is plausible that HSPB1 may play an

220 unknown role in cardiomyopathy. Alternatively, HSPB1 might be involved in 
221 cataract, because HSPB1, CRYAA and CRYAB interact with each other and all

222 can negatively regulate the apoptotic process (Table 4). Studies suggested

223 that lens epithelial cell apoptosis may be a common cellular basis for

224 initiation of non-congenital cataract formation (Li et al. 1995), and inhibition

225 of epithelial cell apoptosis may be one possible mechanism that inhibits

226 cataract development (Nahomi et al. 2013). Our results here argue for further

227 experimental studies to test the possible role of HSPBI CNVs in

228 cardiomyopathy or cataract/blindness in African Americans.

\section{Duplication of ATP2A1 and cardiomyopathy.}

230 Gene ATP2A1 in cluster CA1 is located in a genomic duplication region that

231 occurs only in Caucasians (Table 3). We found that four genes in cluster CA1

232 are enriched with various GO terms that involve ATP2A1 (Cluster CA1 in Table

233 4), and three of those four genes are related to diseases when they are

234 mutated (Cluster CA1 in Table 5).

235 How would ATP2A1 influence health disparities? Among the diseases related

236 to the pathogenic genes in cluster CA1, idiopathic dilated cardiomyopathy

237 occurs less often in Caucasians than in African Americans (Coughlin et al.

238 1993). Based on the fact that ATP2A1 interacts directly with PLN, and that

239 they are both involved in the same biological processes and exist in the same

240 cellular component (Table 4), it is plausible to suggest that duplication of

241 ATP2A1 may lead to the health disparity in idiopathic dilated cardiomyopathy.

242 One possibility is that higher copies of ATP2A1 may offer some benefits to

243 Caucasians. Studies have shown that increased activity of sarco/endoplasmic 
244 reticulum $\mathrm{Ca}^{2+}$-ATPase 1 (SERCA1), which is encoded by ATP2A1, can partially

245 rescue the heart from $\cdot \mathrm{OH}$-induced injury (Hiranandani et al. 2006), and

246 protect the heart from ischemia-reperfusion (I/R) injury (Talukder et al. 2007).

247 Another possibility is that higher copies of ATP2A1 only lead to moderate risk

248 of cardiomyopathy in Caucasians, and this moderate effect is overshadowed

249 by other genetics factors not covered by our CNV dataset.

\section{Remarks, limitations, and future directions}

251 Although genetic factors play a crucial role in health disparities, only a few

252 association studies have been reported in health disparities in common

253 complex diseases, such as breast cancer (Long et al. 2013), prostate cancer

254 (Bensen et al. 2014; Bensen et al. 2013; Xu et al. 2011), type 2 diabetes (Ng

255 et al. 2014) and vascular diseases (Wei et al. 2011).

256 Our study here is closely related to network-based meta-analyses of GWAS

257 results (Atias et al. 2013; Leiserson et al. 2013). One important aim of

258 network-based meta-analysis of GWAS data is to distinguish the bona fide

259 causal gene from other genes in the same haplotype block associated with

260 the significant SNP. Likewise, our network approach aims to predict a

261 potential causal gene from a population-specific CNV that can be associated

262 with pathogenic genes.

263 Noticeably, our method does not require network permutations, whereas 264 many existing methods of network/pathway based meta-analyses of GWAS 265 data do. This difference is because we first partitioned the network into 
266 clusters and then performed association tests. In comparison, many network

267 based GWAS meta-analysis methods use traversal distances to seed genes to

268 evaluate candidate genes. This kind of traversal distance based method

269 generally prohibits pre-partition of network into clusters and require network

270 permutations for estimation of $p$-values. It can be seen that our cluster-

271 based method naturally accommodates multiple candidate genes in the

272 association analysis, whereas traversal distance in a network is by definition

273 often limited to single candidate gene evaluation.

274 The clustering method of MCL that we chose has been consistently reported

275 to work better than several other methods in detecting annotated protein

276 complexes (Pizzuti \& Rombo 2014), is more tolerant to noises in the network

277 datasets (Vlasblom \& Wodak 2009), and is argued to be the most reliable and

278 robust method for network clustering analysis especially when interaction

279 networks contain many noises and missing data (Vlasblom \& Wodak 2009;

280 Wang et al. 2010). Nevertheless, this clustering procedure has introduced

281 some limitations in our analysis.

282 The first major limitation is that the biological meanings of many clusters

283 generated by MCL may be limited or ambiguous. For example, GO

284 enrichment test suggested that cluster AA1 and AA4 are involved in visual

285 perception and eye development, but GO term related to cardiomyopathy

286 was not enriched. Moreover, gene-gene interactions (also known as edges) in

287 our networks are unweighted. Since MCL basically partitions genes into

288 strongly connected groups and separates these groups based on weak-flows 
289 (Lin et al. 2007), MCL essentially partitions networks only based on gene

290 connection patterns (i.e. network topology) in this study. It is known that

291 gene expression can be used to weight gene/protein interactions and thereby

292 improve the biological relevance of gene/protein networks (Csermely et al.

293 2013; Liu \& Chen 2012; Liu et al. 2013; Qin \& Yang 2008; Wu et al. 2012). In

294 the present study, we were not able to use gene expression data sets

295 relevant for health disparity-related diseases - a limitation that we hope to

296 overcome in the future.

297 The second major limitation is the difficulty for parameter optimization due to 298 uneven cluster sizes. Like other clustering methods, MCL yields clusters with

299 uneven sizes, and makes it challenging for us to optimize the inflation

300 parameter to find a level of sensitivity that can be acceptable in all cases.

301 Consequently, significant associations were mostly detected when clusters

302 sizes were moderate but not when cluster sizes were too large. We mitigated

303 this problem to some extent by trying a range of values for the inflation

304 parameter, but an optimal 'default' setting remains a challenge.

305 In future studies, we plan to address these limitations of the present study by 306 integrating functional genomics data sets, such as gene expressions, into

307 gene networks to generate weighted interactions, and by developing step308 wise clustering methods.

309 Conclusions 
310 In this study, gene clusters were inferred from two human gene/protein

311 networks, HPRDNet and MultiNet, by the MCL clustering algorithm with

312 different parameters. Each cluster was ranked using the products of FDR

313 values based on the right-tailed Fisher's exact tests for enrichment of

314 pathogenic or CNV-genes. Five clusters were consistently found to be

315 enriched with both pathogenic genes and genes located in African-American

316 or Caucasian CNVs. In cluster AA1, AA2, AA3 and AA4, gene HSPB1 is

317 duplicated more frequently in African-Americans. In clusters CA1, gene

318 ATP2A1 is duplicated only in Caucasians. All gene clusters are associated with

319 certain diseases that occur more often in one population than in the other.

320 Although we only studied population-preferred CNVs and did not consider the

321 roles of other genetic factors, our computational studies have generated

322 some interesting hypotheses for further experimental studies to understand

323 health disparities in these diseases.

\section{Author contributions}

325 HQ initiated this study. HQ and LY designed the overall project. YJ

326 implemented the methods and performed data analyses. All authors

327 participated in writing.

\section{Acknowledgements}

329 The authors thank three reviewers for constructive comments that have

330 greatly improved the quality and presentation of this work. YJ and LY were 
331 partially supported by Tennessee Higher Education Commission's Center of

332 Excellence in Applied Computational Science and Engineering.

\section{Reference:}

334

335

336

337

338

339

340

341

342

343

344
Atias N, Istrail S, and Sharan R. 2013. Pathway-based analysis of genomic variation data. Curr Opin Genet Dev 23:622-626.

Barabasi AL, Gulbahce N, and Loscalzo J. 2011. Network medicine: a network-based approach to human disease. Nat Rev Genet 12:56-68.

Baranzini SE, Galwey NW, Wang J, Khankhanian P, Lindberg R, Pelletier D, Wu W, Uitdehaag BM, Kappos L, Gene MSAC, Polman CH, Matthews PM, Hauser SL, Gibson RA, Oksenberg JR, and Barnes MR. 2009. Pathway and network-based analysis of genome-wide association studies in multiple sclerosis. Hum Mol Genet 18:2078-2090.

Bensen JT, Xu Z, McKeigue PM, Smith GJ, Fontham ET, Mohler JL, and Taylor JA. 2014. Admixture mapping of prostate cancer in African Americans participating in the North Carolina-Louisiana Prostate Cancer Project (PCaP). Prostate 74:1-9.

Bensen JT, Xu Z, Smith GJ, Mohler JL, Fontham ET, and Taylor JA. 2013. Genetic polymorphism and prostate cancer aggressiveness: a case-only study of 1,536 GWAS and candidate SNPs in African-Americans and EuropeanAmericans. Prostate 73:11-22.

Congdon N, O'Colmain B, Klaver CC, Klein R, Munoz B, Friedman DS, Kempen J, Taylor HR, and Mitchell P. 2004. Causes and prevalence of visual impairment among adults in the United States. Arch Ophthalmol 122:477-485.

Coughlin SS, Labenberg JR, and Tefft MC. 1993. Black-white differences in idiopathic dilated cardiomyopathy: the Washington DC dilated Cardiomyopathy Study. Epidemiology 4:165-172.

Csermely P, Korcsmaros T, Kiss HJ, London G, and Nussinov R. 2013. Structure and dynamics of molecular networks: a novel paradigm of drug discovery: a comprehensive review. Pharmacol Ther 138:333-408.

Eden E, Navon R, Steinfeld I, Lipson D, and Yakhini Z. 2009. GOrilla: a tool for discovery and visualization of enriched $\mathrm{GO}$ terms in ranked gene lists. $B M C$ Bioinformatics 10:48.

Gilman SR, lossifov I, Levy D, Ronemus M, Wigler M, and Vitkup D. 2011. Rare de novo variants associated with autism implicate a large functional network of genes involved in formation and function of synapses. Neuron 70:898-907.

Glessner JT, Wang K, Cai G, Korvatska O, Kim CE, Wood S, Zhang H, Estes A, Brune CW, Bradfield JP, Imielinski M, Frackelton EC, Reichert J, Crawford EL, Munson J, Sleiman PM, Chiavacci R, Annaiah K, Thomas K, Hou C, Glaberson W, Flory J, Otieno F, Garris M, Soorya L, Klei L, Piven J, Meyer KJ, Anagnostou E, Sakurai T, Game RM, Rudd DS, Zurawiecki D, McDougle CJ, Davis LK, Miller J, Posey DJ, Michaels S, Kolevzon A, Silverman JM, Bernier R, Levy SE, Schultz RT, Dawson G, Owley T, McMahon WM, Wassink TH, Sweeney JA, Nurnberger JI, Coon H, Sutcliffe JS, Minshew NJ, Grant SF, Bucan M, Cook EH, Buxbaum JD, Devlin B, Schellenberg GD, and Hakonarson H. 2009. Autism genome-wide copy number variation reveals ubiquitin and neuronal genes. Nature 459:569-573. Hiranandani N, Bupha-Intr T, and Janssen PM. 2006. SERCA overexpression reduces hydroxyl radical injury in murine myocardium. Am J Physiol Heart Circ Physiol 291:H3130-3135. 
Karolchik D, Barber GP, Casper J, Clawson H, Cline MS, Diekhans M, Dreszer TR, Fujita PA, Guruvadoo L, Haeussler M, Harte RA, Heitner S, Hinrichs AS, Learned K, Lee BT, Li CH, Raney BJ, Rhead B, Rosenbloom KR, Sloan CA, Speir ML, Zweig AS, Haussler D, Kuhn RM, and Kent WJ. 2014. The UCSC Genome Browser database: 2014 update. Nucleic Acids Res 42:D764-770.

Khurana E, Fu Y, Chen J, and Gerstein M. 2013. Interpretation of genomic variants using a unified biological network approach. PLoS Comput Biol 9:e1002886.

Lee I, Blom UM, Wang PI, Shim JE, and Marcotte EM. 2011. Prioritizing candidate disease genes by network-based boosting of genome-wide association data. Genome Res 21:1109-1121.

Leiserson MD, Eldridge JV, Ramachandran S, and Raphael BJ. 2013. Network analysis of GWAS data. Curr Opin Genet Dev 23:602-610.

Li WC, Kuszak JR, Dunn K, Wang RR, Ma W, Wang GM, Spector A, Leib M, Cotliar AM, Weiss M, and et al. 1995. Lens epithelial cell apoptosis appears to be a common cellular basis for non-congenital cataract development in humans and animals. J Cell Biol 130:169-181.

Lin C, Cho Y-R, Hwang W-C, Pei P, and Zhang A. 2007. Clustering Methods in a Protein-Protein Interaction Network. In: Hu X, and Pan Y, eds. Knowledge Discovery in Bioinformatics: John Wiley \& Sons, Inc., 319-355.

Liu ZP, and Chen L. 2012. Proteome-wide prediction of protein-protein interactions from high-throughput data. Protein Cell 3:508-520.

Liu ZP, Wang Y, Zhang XS, and Chen L. 2012. Network-based analysis of complex diseases. IET Syst Biol 6:22-33.

Liu ZP, Zhang W, Horimoto K, and Chen L. 2013. Gaussian graphical model for identifying significantly responsive regulatory networks from time course high-throughput data. IET Syst Biol 7:143-152.

Long J, Zhang B, Signorello LB, Cai Q, Deming-Halverson S, Shrubsole MJ, Sanderson M, Dennis J, Michailiou K, Easton DF, Shu XO, Blot WJ, and Zheng W. 2013. Evaluating genome-wide association study-identified breast cancer risk variants in African-American women. PLoS One 8:e58350.

McCarroll SA, and Altshuler DM. 2007. Copy-number variation and association studies of human disease. Nat Genet 39:S37-42.

McElroy JP, Nelson MR, Caillier SJ, and Oksenberg JR. 2009. Copy number variation in African Americans. BMC Genet 10:15.

Mishra GR, Suresh M, Kumaran K, Kannabiran N, Suresh S, Bala P, Shivakumar K, Anuradha N, Reddy R, Raghavan TM, Menon S, Hanumanthu G, Gupta M, Upendran S, Gupta S, Mahesh M, Jacob B, Mathew P, Chatterjee P, Arun KS, Sharma S, Chandrika KN, Deshpande N, Palvankar K, Raghavnath R, Krishnakanth R, Karathia H, Rekha B, Nayak R, Vishnupriya G, Kumar HG, Nagini M, Kumar GS, Jose R, Deepthi P, Mohan SS, Gandhi TK, Harsha HC, Deshpande KS, Sarker M, Prasad TS, and Pandey A. 2006. Human protein reference database--2006 update. Nucleic Acids Res 34:D411-414.

Nahomi RB, Wang B, Raghavan CT, Voss O, Doseff Al, Santhoshkumar P, and Nagaraj RH. 2013. Chaperone peptides of alpha-crystallin inhibit epithelial cell apoptosis, protein insolubilization, and opacification in experimental cataracts. J Biol Chem 288:13022-13035.

National Center for Health Statistics. 2013. Health, United States, 2012: With Special Feature on Emergency Care. Hyattsville, MD.

Ng MC, Shriner D, Chen BH, Li J, Chen WM, Guo X, Liu J, Bielinski SJ, Yanek LR, Nalls MA, Comeau ME, Rasmussen-Torvik LJ, Jensen RA, Evans DS, Sun YV, An P, Patel SR, Lu Y, Long J, Armstrong LL, Wagenknecht L, Yang L, Snively BM, Palmer ND, Mudgal P, Langefeld CD, Keene KL, Freedman BI, Mychaleckyj JC, Nayak U, Raffel LJ, Goodarzi MO, Chen YD, Taylor HA, Jr., Correa A, Sims M, 

Mathias RA, Vaidya $D$, Singleton $A B$, Zonderman AB, Igo RP, Jr., Sedor JR, Kabagambe EK, Siscovick DS, McKnight B, Rice K, Liu Y, Hsueh WC, Zhao W, Bielak LF, Kraja A, Province MA, Bottinger EP, Gottesman O, Cai Q, Zheng W, Blot WJ, Lowe WL, Pacheco JA, Crawford DC, Grundberg E, Rich SS, Hayes MG, Shu XO, Loos RJ, Borecki IB, Peyser PA, Cummings SR, Psaty BM, Fornage M, lyengar SK, Evans MK, Becker DM, Kao WH, Wilson JG, Rotter JI, Sale MM, Liu S, Rotimi CN, and Bowden DW. 2014. Meta-analysis of genome-wide association studies in African Americans provides insights into the genetic architecture of type 2 diabetes. PLoS Genet 10:e1004517.

Online Mendelian Inheritance in Man O. 2014. Baltimore, MD: McKusick-Nathans Institute of Genetic Medicine, Johns Hopkins University.

Peri S, Navarro JD, Amanchy R, Kristiansen TZ, Jonnalagadda CK, Surendranath V, Niranjan V, Muthusamy B, Gandhi TK, Gronborg M, Ibarrola N, Deshpande N, Shanker K, Shivashankar HN, Rashmi BP, Ramya MA, Zhao Z, Chandrika KN, Padma N, Harsha HC, Yatish AJ, Kavitha MP, Menezes M, Choudhury DR, Suresh S, Ghosh N, Saravana R, Chandran S, Krishna S, Joy M, Anand SK, Madavan V, Joseph A, Wong GW, Schiemann WP, Constantinescu SN, Huang L, Khosravi-Far R, Steen H, Tewari M, Ghaffari S, Blobe GC, Dang CV, Garcia JG, Pevsner J, Jensen ON, Roepstorff P, Deshpande KS, Chinnaiyan AM, Hamosh A, Chakravarti A, and Pandey A. 2003. Development of human protein reference database as an initial platform for approaching systems biology in humans. Genome Res 13:2363-2371.

Pizzuti C, Rombo S, and Marchiori E. 2012. Complex Detection in Protein-Protein Interaction Networks: A Compact Overview for Researchers and Practitioners. In: Giacobini M, Vanneschi L, and Bush W, eds. Evolutionary Computation, Machine Learning and Data Mining in Bioinformatics: Springer Berlin Heidelberg, 211-223.

Pizzuti C, and Rombo SE. 2014. Algorithms and tools for protein-protein interaction networks clustering, with a special focus on population-based stochastic methods. Bioinformatics 30:1343-1352.

Pounds S, and Cheng C. 2006. Robust estimation of the false discovery rate. Bioinformatics 22:1979-1987.

Prasad TSK, Goel R, Kandasamy K, Keerthikumar S, Kumar S, Mathivanan S, Telikicherla D, Raju R, Shafreen B, Venugopal A, Balakrishnan L, Marimuthu A, Banerjee S, Somanathan DS, Sebastian A, Rani S, Ray S, Harrys Kishore CJ, Kanth S, Ahmed M, Kashyap MK, Mohmood R, Ramachandra YL, Krishna V, Rahiman BA, Mohan S, Ranganathan P, Ramabadran S, Chaerkady R, and Pandey A. 2009. Human Protein Reference Database--2009 update. Nucleic Acids Res 37:D767-772.

Qin H, and Yang L. 2008. Detection of changes in transitive associations by shortestpath analysis of protein interaction networks integrated with gene expression profiles. BioMedical Engineering and Informatics, 2008 BMEI 2008 International Conference on: IEEE. p 418-423.

R Development Core Team. 2013. R: A language and environment for statistical computing. Vienna, Austria: R Foundation for Statistical Computing.

Ramos E, and Rotimi C. 2009. The A's, G's, C's, and T's of health disparities. BMC Med Genomics 2:29.

Sharma A, Gulbahce N, Pevzner SJ, Menche J, Ladenvall C, Folkersen L, Eriksson P, Orho-Melander M, and Barabasi AL. 2013. Network-based analysis of genome wide association data provides novel candidate genes for lipid and lipoprotein traits. Mol Cell Proteomics 12:3398-3408. 
483

484

485

486

487

488

489

490

491

492

493

494

495

496

497

498

499

500

501

502

503

504

505

506

507

508

Sherry ST, Ward MH, Kholodov M, Baker J, Phan L, Smigielski EM, and Sirotkin K. 2001. dbSNP: the NCBI database of genetic variation. Nucleic Acids Res 29:4.

Talukder MA, Kalyanasundaram A, Zhao X, Zuo L, Bhupathy P, Babu GJ, Cardounel AJ, Periasamy M, and Zweier JL. 2007. Expression of SERCA isoform with faster $\mathrm{Ca} 2+$ transport properties improves postischemic cardiac function and $\mathrm{Ca} 2+$ handling and decreases myocardial infarction. Am J Physiol Heart Circ Physiol 293:H2418-2428.

van Dongen S. 2000. Graph Clustering by Flow Simulation PhD. University of Utrecht.

Vidal M, Cusick ME, and Barabasi AL. 2011. Interactome networks and human disease. Cell 144:986-998.

Vlasblom J, and Wodak SJ. 2009. Markov clustering versus affinity propagation for the partitioning of protein interaction graphs. BMC Bioinformatics 10:99.

Wang J, Li M, Deng Y, and Pan Y. 2010. Recent advances in clustering methods for protein interaction networks. BMC Genomics 11 Suppl 3:S10.

Wei P, Milbauer LC, Enenstein J, Nguyen J, Pan W, and Hebbel RP. 2011. Differential endothelial cell gene expression by African Americans versus Caucasian Americans: a possible contribution to health disparity in vascular disease and cancer. BMC Med 9:2.

Wu C, Zhu J, and Zhang X. 2012. Integrating gene expression and protein-protein interaction network to prioritize cancer-associated genes. BMC Bioinformatics $13: 182$.

Xu Z, Bensen JT, Smith GJ, Mohler JL, and Taylor JA. 2011. GWAS SNP Replication among African American and European American men in the North CarolinaLouisiana prostate cancer project (PCaP). Prostate 71:881-891.

Zhao M, and Zhao Z. 2013. CNVannotator: a comprehensive annotation server for copy number variation in the human genome. PLoS One 8:e80170. 
1

Overview of our approach to identify CNVs associated with health disparities

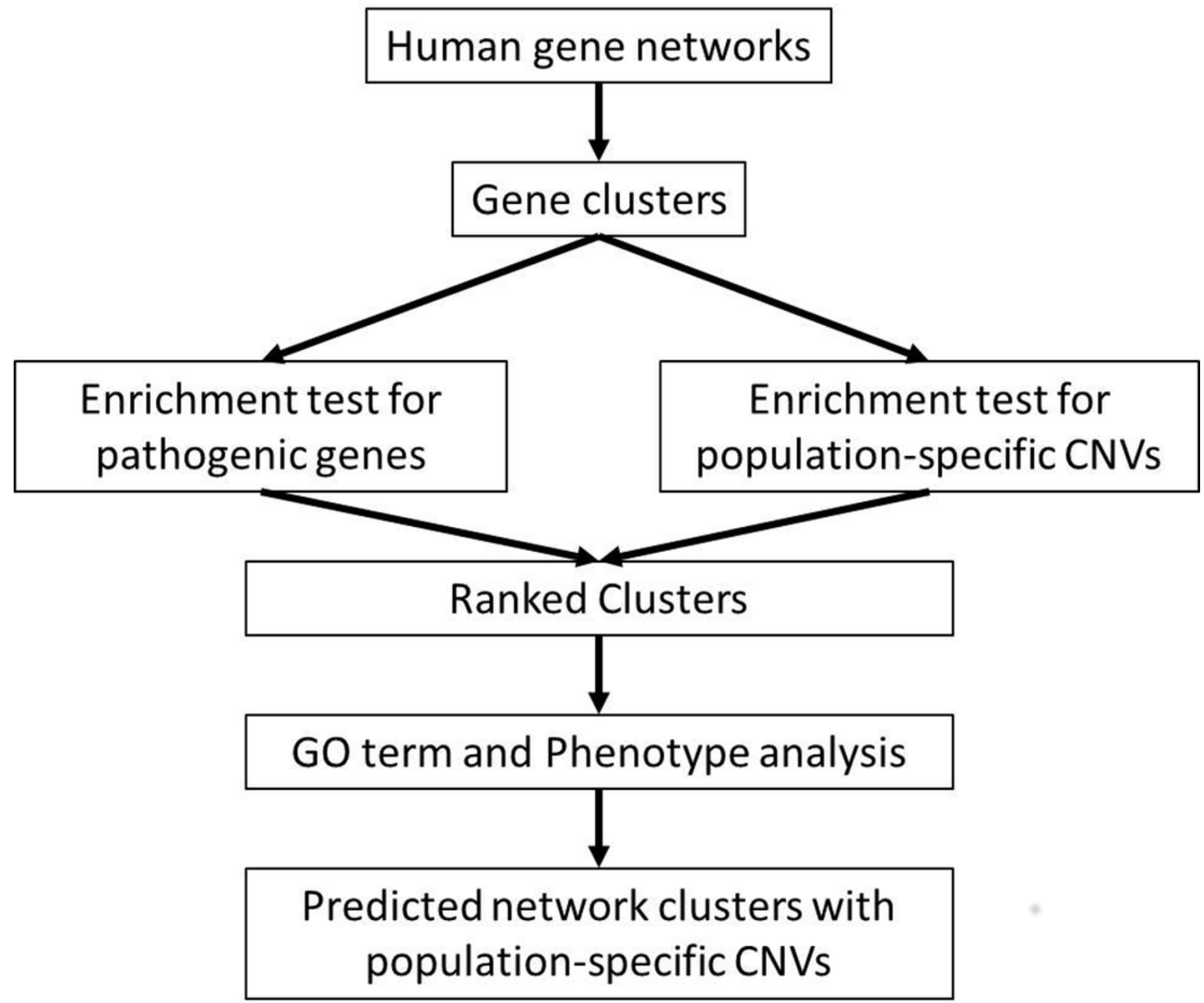




\section{2}

Graph representations of selected clusters for biological significance analysis.

Each rounded rectangle represents a gene and each gray line represents a gene-gene interaction. Black rounded rectangles represent non-pathogenic genes and orange rounded rectangles represent pathogenic genes. Genes labeled with red or blue ovals are located in African American CNVs or in Caucasian CNVs. Genes with Green lines share the same GO terms. In each cluster, different line types represent the enrichment of different $\mathrm{GO}$ terms. Line types shown in different clusters refer to the enrichment of different $\mathrm{GO}$ terms.

(A)

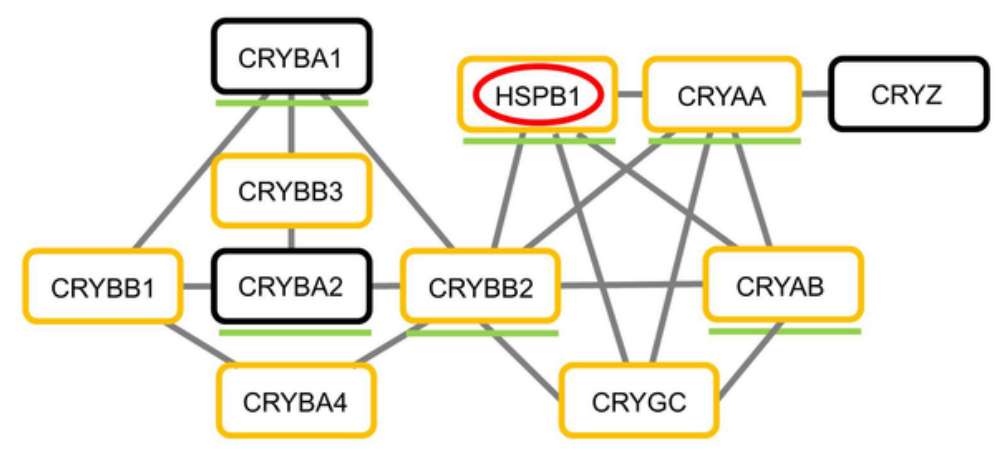

(B)

\section{Cluster AA4}

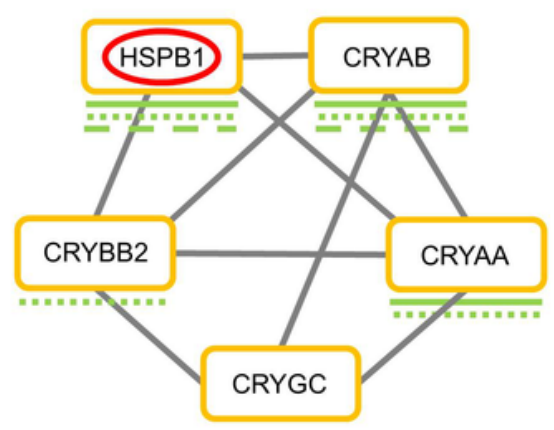

(C) Cluster CA1

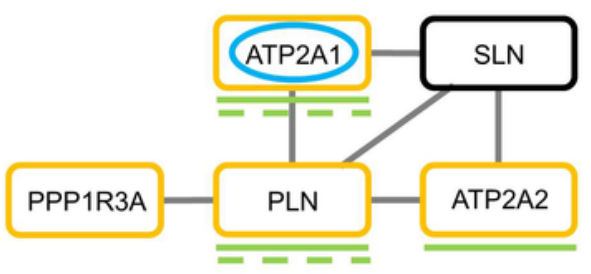

Non-pathogenic genes

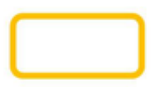

pathogenic genes

Genes affected by CNVs that occur more frequently in African Americans

Genes affected by CNVs that occur more frequently in Caucasians

Genes in which GO terms are enriched.

In each cluster, different line types refer to different GO terms. Same line type refer to different GO terms in different clusters. 


\section{Table $\mathbf{1}_{\text {(on next page) }}$}

Contingency tables

Table 1A. Contingency Table for Fisher's exact Test on Pathogenic Genes. Table 1B.

Contingency Table for Fisher's exact Test on CNV genes. For each cluster, contingency tables were constructed for right-tailed Fisher's exact Tests. Table $1 \mathrm{~A}$ is for pathogenic significance test, and Table 1B is for tests of enrichment significance of CNV genes (CNV_AA or CNV_CA genes). $Q$ and $q$ are the number of pathogenic genes in the whole networks and that in current cluster, respectively. $\mathrm{N}$ and $\mathrm{m}$ are the number of genes in whole networks and that in current cluster, respectively. $\mathrm{S}$ and $\mathrm{s}$ are the number of CNV_AA or CNV_CA genes in the whole networks and that in current cluster, respectively. 
Table 1A. Contingency Table for Fisher's exact Test on Pathogenic Genes

\begin{tabular}{l|cc|c}
\hline & Pathogenic Genes & Non-pathogenic Genes & Total \\
\hline Genes in this cluster & $\mathrm{q}$ & $\mathrm{m}-\mathrm{q}$ & $\mathrm{m}$ \\
Genes in other clusters & $\mathrm{Q}-\mathrm{q}$ & $\mathrm{N}-\mathrm{Q}-\mathrm{m}+\mathrm{q}$ & $\mathrm{N}-\mathrm{m}$ \\
\hline Total & $\mathrm{Q}$ & $\mathrm{N}-\mathrm{Q}$ & $\mathrm{N}$ \\
\hline
\end{tabular}

Table 1B. Contingency Table for Fisher's exact Test on CNV genes

\begin{tabular}{l|ccc}
\hline & CNV Genes & Non-CNV Genes & Total \\
\hline Genes in this cluster & $\mathrm{S}$ & $\mathrm{m}-\mathrm{s}$ & $\mathrm{m}$ \\
Genes in other clusters & $\mathrm{S}-\mathrm{s}$ & $\mathrm{N}-\mathrm{S}-\mathrm{m}+\mathrm{s}$ & $\mathrm{N}-\mathrm{m}$ \\
\hline Total & $\mathrm{S}$ & $\mathrm{N}-\mathrm{S}$ & $\mathrm{N}$ \\
\hline
\end{tabular}

For each cluster, contingency tables were constructed for right-tailed Fisher's exact Tests. Table 1A is for pathogenic significance test, and Table $1 \mathrm{~B}$ is for tests of enrichment significance of CNV genes (CNV_AA or CNV_CA genes). Q and $q$ are the number of pathogenic genes in the whole networks and that in current cluster, respectively. $\mathrm{N}$ and $\mathrm{m}$ are the number of genes in whole networks and that in current cluster, respectively. $\mathrm{S}$ and $\mathrm{S}$ are the number of $\mathrm{CNV}$ _AA or CNV_CA genes in the whole networks and that in current cluster, respectively. 
Table 2 (on next page)

Cluster analysis results for HPRDNet and MultiNet

Selected clusters were listed. CNV_AA and CNV_CA are CNV-related genes. 
Table 2. Cluster analysis results for HPRDNet and MultiNet

\begin{tabular}{lccccc}
\hline Network & $\begin{array}{c}\text { Cluster } \\
\text { Name }\end{array}$ & CNV_AA & CNV_CA & $\begin{array}{c}\text { Pathogenic } \\
\text { gene number }\end{array}$ & $\begin{array}{c}\text { Cluster } \\
\text { Size }\end{array}$ \\
\hline HPRDNet & AA1 & HSPB1 & - & 8 & 11 \\
& AA2 & HSPB1 & - & 8 & 12 \\
& AA3 & HSPB1 & - & 8 & 13 \\
\multirow{4}{*}{ MultiNet } & CA1 & - & ATP2A1 & 4 & 5 \\
& AA4 & HSPB1 & - & 5 & 5 \\
& CA1 & - & ATP2A1 & 4 & 5 \\
\hline Selected clusters were listed. CNV_AA and CNV_CA are CNV-related \\
genes.
\end{tabular}


Table 3 (on next page)

Detected genes with potential roles in health disparity and their located CNVs

Chr represents chromosomes. CNV Regions are regions of CNVs identified in more than a single individual; all CNVs listed have a type of Duplication, referring to one copy increase. CNV Regions and Types are from the CNV map (McElroy et al. 2009). CNV Occurrence preference describes in which population those CNVs have higher occurrence frequency. 
Table 3. Detected genes with potential roles in health disparity and their located CNVs

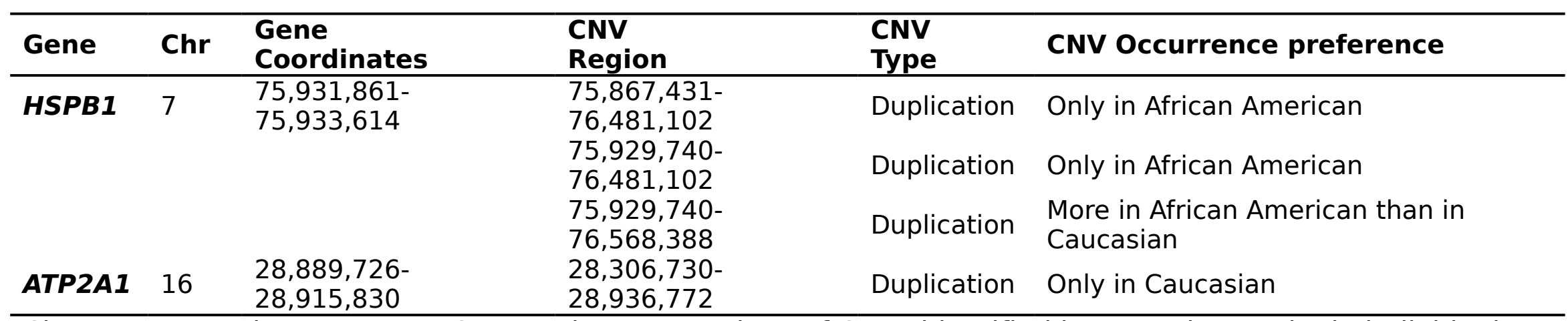

Chr represents chromosomes. CNV Regions are regions of CNVs identified in more than a single individual; all CNVs listed have a type of Duplication, referring to one copy increase. CNV Regions and Types are from the CNV map (McElroy et al. 2009). CNV Occurrence preference describes in which population those CNVs have higher occurrence frequency. 


\section{Table 4(on next page)}

Enriched GO terms with CNV-genes in the identified network clusters

Biological relevance of network clusters was analyzed by GOrilla (Eden et al. 2009) to search for enriched gene ontology (GO) terms. Genes in the selected clusters were used as target genes, and all genes in the networks were treated as background genes. Three types of GO terms were analyzed: biological process, molecular function and cellular component. The default $p$-value threshold $\left(1 \times 10^{-3}\right)$ was used. In the results, enriched $\mathrm{GO}$ terms that are associated with CNV_AA gene HSPB1 and CNV_CA gene ATP2A1 were selected and listed in the table.*When multiple enriched GO terms show similar meanings, we only presented the most general terms. 
Table 4. Enriched GO terms with CNV-genes in the identified network clusters

\begin{tabular}{|c|c|c|c|c|}
\hline Clusters & Involved Genes & GO Domain & GO ID & GO term \\
\hline AA1 & $\begin{array}{l}\text { HSPB1, CRYAA, CRYAB, } \\
\text { CRYBB2, CRYBA1, CRYBA2 }\end{array}$ & Molecular Function & GO:0042802 & identical protein binding \\
\hline \multirow[t]{5}{*}{ AA4 } & $H S P B 1, C R Y A A, C R Y A B$ & Biological Process & GO:0043086 & negative regulation of catalytic activity \\
\hline & & Biological Process & GO:0043066 & negative regulation of apoptotic process \\
\hline & & Biological Process & GO:0043069 & negative regulation of programmed cell death \\
\hline & HSPB1, CRYAA, CRYAB, CRYBB2 & Molecular Function & GO:0042802 & identical protein binding \\
\hline & $H S P B 1, C R Y A B$ & Cellular Component & GO:0030018 & $\mathrm{Z}$ disc \\
\hline \multirow[t]{9}{*}{$\mathrm{CA} 1 *$} & $A T P 2 A 1, A T P 2 A 2, P L N, S L N$ & Biological Process & GO:0090257 & regulation of muscle system process \\
\hline & & Biological Process & GO:0006816 & calcium ion transport \\
\hline & & Cellular Component & GO:0033017 & sarcoplasmic reticulum membrane \\
\hline & $A T P 2 A 1, A T P 2 A 2, P L N$ & Biological Process & GO:0003012 & muscle system process \\
\hline & & Biological Process & GO:0006874 & cellular calcium ion homeostasis \\
\hline & & Cellular Component & GO: 1902495 & transmembrane transporter complex \\
\hline & $A T P 2 A 1, A T P 2 A 2, S L N$ & Cellular Component & GO:0016529 & sarcoplasmic reticulum \\
\hline & $A T P 2 A 1, A T P 2 A 2$ & Biological Process & GO:0032470 & $\begin{array}{l}\text { positive regulation of endoplasmic reticulum calcium ion } \\
\text { concentration }\end{array}$ \\
\hline & & Cellular Component & GO:0031095 & platelet dense tubular network membrane \\
\hline
\end{tabular}

Biological relevance of network clusters was analyzed by GOrilla (Eden et al. 2009) to search for enriched gene ontology (GO) terms. Genes in the selected clusters were used as target genes, and all genes in the networks were treated as background genes. Three types of GO terms were analyzed: biological process, molecular function and cellular component. The default $p$-value threshold $\left(1 \times 10^{-3}\right)$ was used. In the results, enriched GO terms that are associated with CNV_AA gene HSPBI and CNV_CA gene ATP2A1 were selected and listed in the table.*When multiple enriched $\bar{G}$ O terms show similar meanings, we only presented the most general terms. 
Table 5 (on next page)

Associated diseases of genes with enriched GO terms.

Only GO terms that contain CNV-genes are studied due to our focus on the role of CNV-genes in health disparity. 
Table 5. Associated diseases of genes with enriched GO terms.

\begin{tabular}{lll}
\hline Cluster & Gene & Associated Disease \\
\hline AA1 & HSPB1 & Axonal Charcot-Marie-Tooth disease type 2F \\
and & Distal hereditary motor neuronopathy type 2B \\
AA4 & CRYAA & Multiple types of cataract 9 \\
& MrYAB & Multiple types of cataract 16 \\
& Dilated cardiomyopathy-1II \\
& & Myofibrillar myopathy-2 \\
& & CRYAB-related fatal infantile hypertonic myofibrillar \\
& & myopathy \\
& Multiple types of Cataract 3 \\
\hline CA1 & ATP2A1 & Brody myopathy \\
& ATP2A2 & Acrokeratosis verruciformis \\
& Darier disease \\
& DLN & Dilated cardiomyopathy-1P \\
& Familial hypertrophic cardiomyopathy-18 \\
\hline Only GO terms that contain CNV-genes are studied due to our focus on \\
the role of CNV-genes in health disparity.
\end{tabular}

